\title{
Patiromer to Enable Spironolactone Use in the Treatment of Patients with Resistant Hypertension and Chronic Kidney Disease: Rationale and Design of the AMBER Study
}

\author{
Rajiv Agarwal $^{\mathrm{a}}$ Patrick Rossignol $^{\mathrm{b}}$ Dahlia Garza ${ }^{\mathrm{c}}$ Martha R. Mayo ${ }^{\mathrm{c}}$ \\ Suzette Warren ${ }^{c}$ Susan Arthur ${ }^{c}$ Alain Romero ${ }^{c}$ William B. White ${ }^{d}$ \\ Bryan Williams ${ }^{\mathrm{e}}$
}

\begin{abstract}
a Department of Medicine, Division of Nephrology, Indiana University School of Medicine, Indianapolis, IN, USA; ${ }^{b}$ Inserm 1433 CIC-P CHRU de Nancy, University of Lorraine and FCRIN INI-CRCT, Nancy, France; ' Relypsa, Inc., a Vifor Pharma Group Company, Redwood City, CA, USA; ${ }^{\mathrm{d} C a l h o u n ~ C a r d i o l o g y ~ C e n t e r, ~ U n i v e r s i t y ~ o f ~ C o n n e c t i c u t ~ S c h o o l ~ o f ~}$ Medicine, Farmington, CT, USA; ${ }^{\mathrm{e}}$ Institute of Cardiovascular Sciences University College London (UCL) and National Institute for Health Research (NIHR) UCL/UCL Hospitals Biomedical Research Centre, London, UK
\end{abstract}

\section{Keywords}

Chronic kidney disease · Hyperkalemia · Patiromer ·

Resistant hypertension · Spironolactone

\begin{abstract}
Background: While chronic kidney disease (CKD) is common in resistant hypertension (RHTN), prior studies evaluating mineralocorticoid receptor antagonists excluded patients with reduced kidney function due to risk of hyperkalemia. AMBER (ClinicalTrials.gov identifier NCT03071263) will evaluate if the potassium-binding polymer patiromer used concomitantly with spironolactone in patients with RHTN and CKD prevents hyperkalemia and allows more persistent spironolactone use for hypertension management. Methods: Randomized, double-blind, placebo-controlled parallel group 12-week study of patiromer and spironolactone versus placebo and spironolactone in patients with uncontrolled RHTN and CKD. RHTN is defined as unattended systolic automated office blood pressure (AOBP) of
\end{abstract}

$135-160 \mathrm{~mm} \mathrm{Hg}$ during screening despite taking $\geq 3$ antihypertensives, including a diuretic, and an angiotensin-converting enzyme inhibitor or an angiotensin receptor blocker (unless not tolerated or contraindicated). The CKD inclusion criterion is an estimated glomerular filtration rate (eGFR) of 25 to $\leq 45 \mathrm{~mL} / \mathrm{min} / 1.73 \mathrm{~m}^{2}$. Screening serum potassium must be $4.3-5.1 \mathrm{mEq} / \mathrm{L}$. The primary efficacy endpoint is the between-group difference (spironolactone plus patiromer versus spironolactone plus placebo) in the proportion of patients remaining on spironolactone at Week 12. Results: Baseline characteristics have been analyzed as of March 2018 for 146 (of a targeted 290) patients. Mean (SD) baseline age is 69.3 (10.9) years; $52.1 \%$ are male, $99.3 \%$ White, and $47.3 \%$ have diabetes. Mean (SD) baseline serum potassium is $4.68(0.25) \mathrm{mEq} / \mathrm{L}$, systolic AOBP is $144.3(6.8) \mathrm{mm} \mathrm{Hg}$, eGFR is 35.7 (7.7) $\mathrm{mL} / \mathrm{min} / 1.73 \mathrm{~m}^{2}$. Conclusion: AMBER will define the ability of patiromer to facilitate the use of spironolactone, an effective antihypertensive therapy for patients with RHTN and CKD.

(c) 2018 The Author(s)

Published by S. Karger AG, Basel

\begin{tabular}{ll}
\hline KARGER & $\begin{array}{l}\text { ( ) 2018 The Author(s) } \\
\text { Published by S. Karger AG, Basel }\end{array}$ \\
E-Mail karger@karger.com & This article is licensed under the Creative Commons Attribution- \\
www.karger.com/ajn & $\begin{array}{l}\text { NonCommercial-NoDerivatives 4.0 International License (CC BY- } \\
\text { NC-ND) (http://www.karger.com/Services/OpenAccessLicense). } \\
\text { Usage and distribution for commercial purposes as well as any dis- } \\
\text { tribution of modified material requires written permission. }\end{array}$
\end{tabular}

Rajiv Agarwal, MD

Department of Medicine, Division of Nephrology

Indiana University, and RLR VA Medical Center

1481 West 10th Street, 111N, Indianapolis, IN 46202 (USA)

E-Mail ragarwal@iu.edu 


\section{Background and Study Rationale}

Resistant hypertension (RHTN) is defined by blood pressure remaining above the treatment goal despite treatment with optimally tolerated doses of 3 antihypertensive agents from different drug classes, including a diuretic [1]. In addition to a diuretic, most practice guidelines recommend treatment with an angiotensinconverting enzyme inhibitor (ACEI) or angiotensin receptor blocker (ARB) and a calcium channel blocker in these patients [2-7]. Treatment-RHTN remains a significant medical problem, with prevalence estimates of up to $8 \%$ among treated hypertensive patients evaluated by 24-h ambulatory blood pressure monitoring [8], and approaching $50 \%$ in specific cohorts, such as patients with chronic kidney disease (CKD) with proteinuria $[9,10]$.

Despite the inhibition of the renin-angiotensinaldosterone system with an ACEI or ARB, RHTN may result from abnormal sodium retention caused by aldosterone breakthrough, a phenomenon affecting 30-40\% of patients treated with an ACEI or ARB over 1 year [11]. In non-epithelial tissues, aldosterone-induced activation of mineralocorticoid receptors in the presence of high extracellular sodium levels promotes tissue inflammation and injury, which may contribute to the progression of CKD and cardiovascular disease [12-14]. Together, these observations provide the rationale for use of aldosterone antagonists (mineralocorticoid receptor antagonists [MRAs]) such as spironolactone in patients with RHTN [15].

Two meta-analyses of clinical and observational studies conducted from 2002 to 2013 concluded that spironolactone effectively reduces blood pressure in patients with RHTN, although the studies were often nonrandomized, and comparison between other treatment options was limited $[16,17]$. Subsequent to these meta-analyses, the PATHWAY-2 study, a randomized, double-blind, crossover study, evaluated patients with RHTN rotated through 12 weeks of add-on treatment with spironolactone, bisoprolol, doxazosin, or placebo [18]. Spironolactone was found to be significantly more effective than the other drugs in reducing blood pressure, regardless of plasma renin levels, although most effective in those with the lowest renin levels. Most RHTN studies evaluating spironolactone have excluded patients with significant CKD due to the risk of hyperkalemia. In a meta-analysis, the addition of spironolactone to an ACEI or ARB doubled the risk of hyperkalemia in patients with mild to moderate $\mathrm{CKD}$, which was dependent on baseline estimated glomerular filtration rate (eGFR), serum potassium $\left(\mathrm{K}^{+}\right)$ level, drug dose, and concomitant medications [19]. Similar findings were reported in an observational study, where addition of an MRA to a diuretic-renin-angiotensin-aldosterone system inhibitor regimen was most likely to cause hyperkalemia in patients with baseline eGFR $\leq 45 \mathrm{~mL} / \mathrm{min} / 1.73 \mathrm{~m}^{2}$ and serum $\mathrm{K}^{+}>4.5 \mathrm{mEq} / \mathrm{L}$ [20]. The development of potassium binders with improved tolerability may allow for increased persistence of MRAs in CKD patients with RHTN by reducing the risk of hyperkalemia.

Patiromer is a sodium-free, non-absorbed, $\mathrm{K}^{+}$-binding polymer used for lowering serum $\mathrm{K}^{+}$in patients with hyperkalemia [21, 22]. Previously, patiromer prevented hyperkalemia in spironolactone-treated heart failure patients with eGFR $<60 \mathrm{~mL} / \mathrm{min} / 1.73 \mathrm{~m}^{2}$ and a history of hyperkalemia [23]. These findings in a heart failure population support the evaluation of patiromer as a therapy to prevent hyperkalemia when RHTN patients are treated with spironolactone, since its use in CKD is often limited by the risk of hyperkalemia [6].

\section{Methods}

This is a randomized, double-blind, placebo controlled, parallel group study of patiromer for the enablement of spironolactone use for blood pressure control in patients with RHTN and CKD (AMBER; ClinicalTrials.gov identifier NCT03071263). This multicenter, multinational study will compare patiromer versus placebo with concomitant spironolactone in patients with RHTN and CKD. AMBER is ongoing, and began enrolling patients on January 23,2017 . The study consists of a screening/run-in period of up to 4 weeks, a double-blind treatment period of 12 weeks, and a followup visit scheduled 2 weeks after the treatment period or early termination (Fig. 1).

\section{Study Oversight and Eligibility}

The study is being conducted in accordance with the Declaration of Helsinki and in compliance with International Conference for Harmonisation E6 Guidelines for Good Clinical Practice and all applicable local and national regulations governing the conduct of human clinical trials. Study sites must obtain the approval from the Institutional Review Board/Independent Ethics Committee before performing any study-related procedures, and all patients must provide written informed consent before participating.

Patients $\geq 18$ years old with uncontrolled RHTN and an eGFR of $25-45 \mathrm{~mL} / \mathrm{min} / 1.73 \mathrm{~m}^{2}$ are eligible to participate in the study. Complete lists of inclusion and exclusion criteria are given in online supplemental Tables 1, 2 (for all online suppl. material, see www.karger.com/doi/10.1159/000492622). Prohibited medications are listed in online supplemental Table 3.

The screening/run-in period consists of 4 visits (S1, S2, S3, and S4), each separated by 4 to 10 days, and is designed to ensure that patients are on stable doses of medication, have true treatmentRHTN, can properly and reliably use a home blood pressure (HBP) 


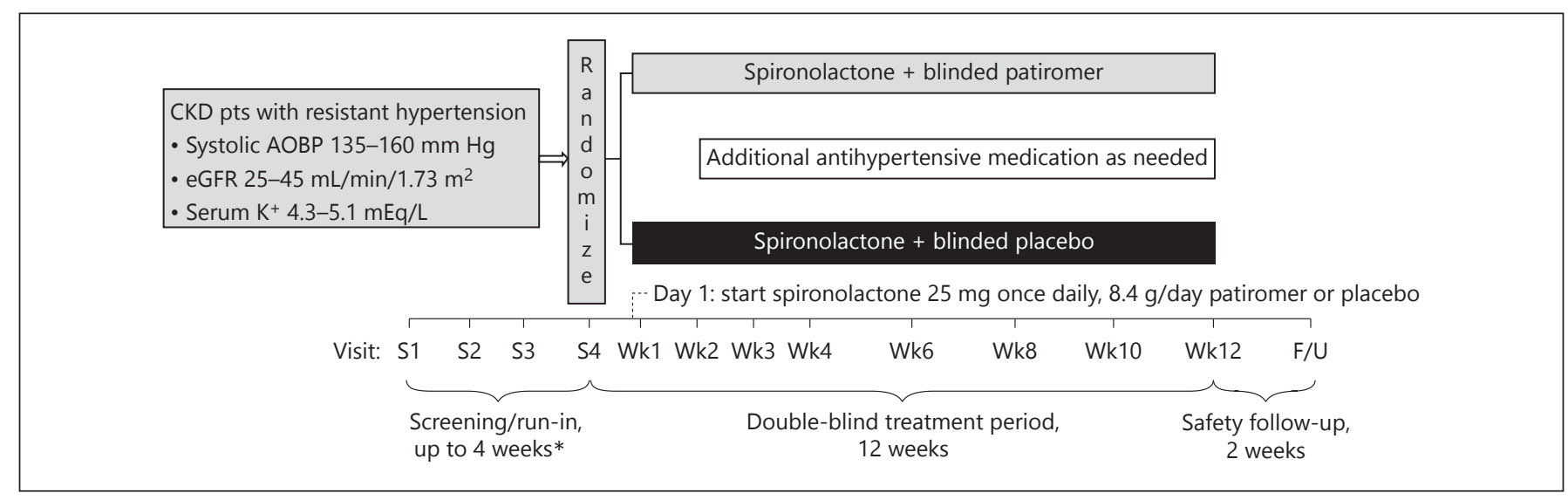

Fig. 1. AMBER study design. AOBP, automated office blood pressure; CKD, chronic kidney disease; eGFR, estimated glomerular filtration rate; HBP, home blood pressure. * To ensure eligibility criteria, stable medication, and competent use of HBP monitor.

monitor, and meet all inclusion criteria. At each visit after the initial screening visit, 2 types of office blood pressure measurements will be made on the patient: Automated office blood pressure (AOBP) and self-measured blood pressure (SMBP).

\section{Automated Office Blood Pressure}

AOBP will be performed by an oscillometric blood pressure monitoring device (Intellisense ${ }^{\circledR}$ HEM-907; Omron Healthcare Inc., Kyoto, Japan). AOBP will be measured in triplicate. The device is programmed to allow a 5 -min rest period before initiating the sequence of triplicate measurements, with a 1-min interval between each measurement. The site staff leaves the room for these automated measurements.

\section{Self-Measured Blood Pressure}

At the first visit, patients are provided with an HBP monitor (Tel-O-Graph ${ }^{\circledR}$, I.E.M. GmbH, Stolberg, Germany). Patients are trained in its use, and are instructed to measure HBP in triplicate twice daily after $5 \mathrm{~min}$ of seated rest at the same times each day (e.g., 8:00 am and 8:00 pm). For each scheduled office visit, patients are instructed to bring their HBP monitor with them. Immediately following the measurement of AOBP, patients will then take SMBP in triplicate before site staff returns to the room. If a patient does not bring their HBP device, then only AOBP will be taken during that visit (SMBP data will be recorded as missing).

\section{Treatment Assignment}

Patients meeting all eligibility criteria at the final screening visit will be stratified by the local $\mathrm{K}^{+}$measurement ( 4.3 to $<4.7$ vs. 4.7 to $5.1 \mathrm{mEq} / \mathrm{L}$ ) and history of diabetes (yes versus no), then randomized (1:1) to receive patiromer or placebo in addition to openlabel spironolactone. The blinded study drug will be provided in packets as a powder for oral suspension, with each packet containing patiromer $(4.2 \mathrm{~g})$ or microcrystalline cellulose placebo. The treatment assignment will be determined via an interactive web response system, with study personnel blinded to the results. All randomized patients will be instructed when to take spironolactone, patiromer or placebo, and their antihypertensive medica- tions, starting on Day 1 of the randomized treatment period. Visits during the treatment period are weekly (Weeks 1-4) and then biweekly (Weeks 6-12).

\section{Spironolactone}

Open-label spironolactone will be started at $25 \mathrm{mg}$ once daily and increased to $50 \mathrm{mg}$ once daily at Week 3 in patients with systolic AOBP $\geq 120 \mathrm{~mm} \mathrm{Hg}$ and $\mathrm{K}^{+} \leq 5.1 \mathrm{mEq} / \mathrm{L}$ (as shown in the spironolactone dosing algorithm in Fig. 2). Patients with systolic AOBP $\geq 120 \mathrm{~mm} \mathrm{Hg}$ and serum $\mathrm{K}^{+}>5.1 \mathrm{mEq} / \mathrm{L}$ at Week 3 will continue on the $25-\mathrm{mg}$ spironolactone dose until the first subsequent visit at which serum $\mathrm{K}^{+}$is $\leq 5.1 \mathrm{mEq} / \mathrm{L}$ (and systolic AOBP remains $\geq 120 \mathrm{~mm} \mathrm{Hg}$ ), at which time the spironolactone dose will be raised to $50 \mathrm{mg}$. Patients with systolic AOBP $<120 \mathrm{~mm} \mathrm{Hg}$ at Week 3 will continue on the 25-mg dose. At any visit, if a patient experiences hypotensive symptoms, with systolic AOBP $<120 \mathrm{~mm} \mathrm{Hg}$, or if systolic AOBP is $<100 \mathrm{~mm} \mathrm{Hg}$, the spironolactone dose may be reduced to $25 \mathrm{mg}$ every other day or discontinued at the investigator's discretion. If spironolactone is discontinued, double-blind study drug (patiromer or placebo) will be discontinued at the same time. Patients who discontinue spironolactone and patiromer/placebo for any reason will remain in the study and be treated with standard medical care based on the investigator's clinical judgment. Dietary counseling will also be provided at each visit in accordance with the standard practices of the investigator.

\section{Patiromer}

Patients will initiate study medication with 2 packets daily taken with food at least $3 \mathrm{~h}$ before or $3 \mathrm{~h}$ after other medications, including spironolactone. Dosing adjustments will be made at intervals of $\geq 1$ week in 2-packet/day increments upward for local serum $\mathrm{K}^{+}>5.1 \mathrm{mEq} / \mathrm{L}$ and downward for serum $\mathrm{K}^{+}<4.0 \mathrm{mEq} / \mathrm{L}$ (as shown in the patiromer/placebo dosing algorithm in Fig. 3). The maximum daily dosage is 6 packets; the minimum is 0 packets. Patients who develop serum $\mathrm{K}^{+} \geq 5.5 \mathrm{mEq} / \mathrm{L}$ that cannot be managed with blinded patiromer/placebo dosage escalation will discontinue spironolactone and patiromer/placebo treatments. These patients will remain in the study and will be followed per protocol, with hyperkalemia treated using standard of care. 


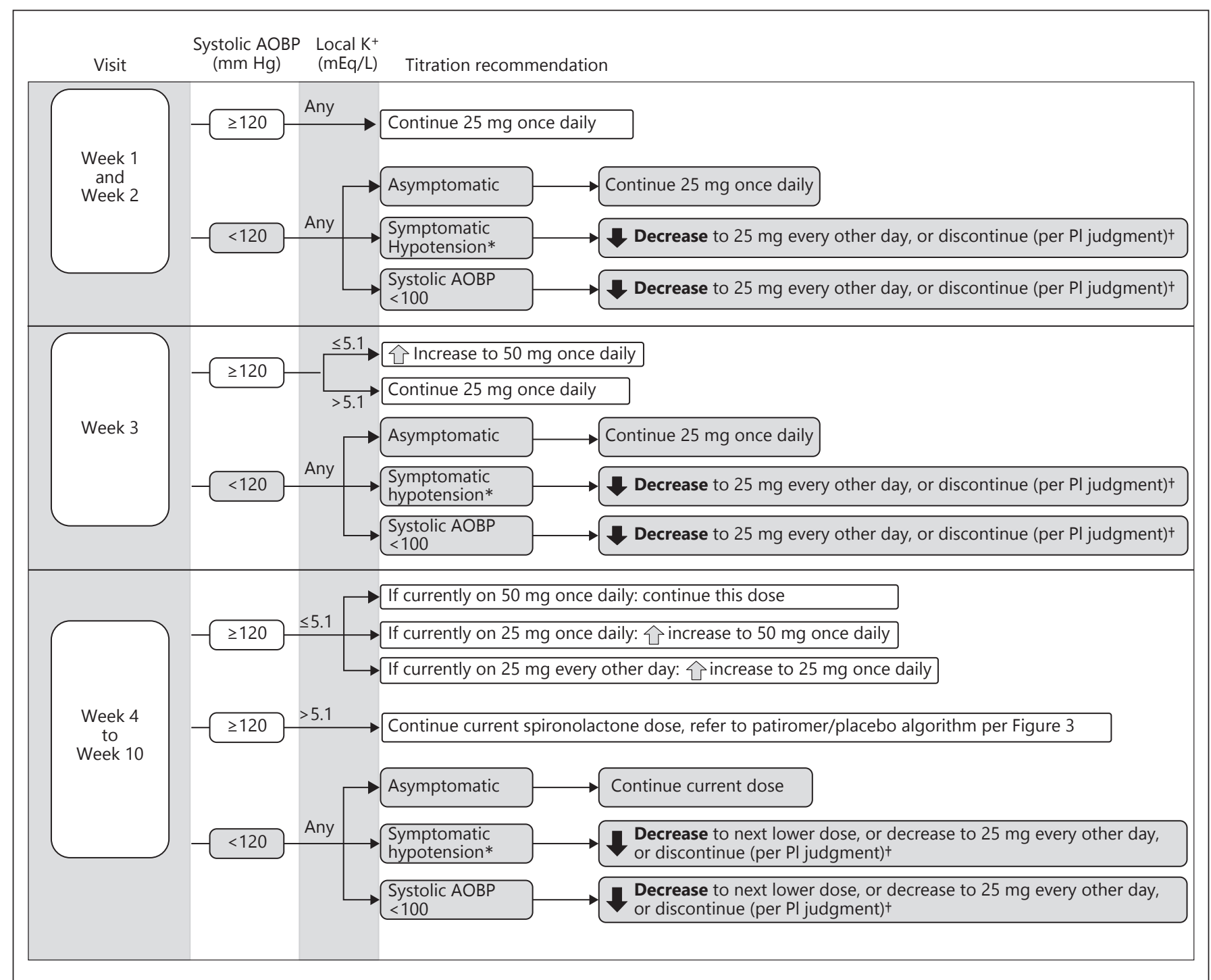

Fig. 2. Spironolactone dosing algorithm. AOBP, automated office blood pressure; $\mathrm{K}^{+}$, potassium; PI, principal investigator. * Investigator determined. ${ }^{\dagger}$ If spironolactone is discontinued, patiromer/placebo must be discontinued at the same time.

\section{Study Endpoints}

The primary endpoint is the difference in the proportion of patients remaining on spironolactone at Week 12 between treatment groups (spironolactone plus patiromer versus spironolactone plus placebo). A key secondary endpoint is the difference in systolic AOBP from baseline to Week 12 (or to the last available AOBP before addition of any new antihypertensive medications or change in any of the baseline antihypertensive medications) between treatment groups. Other endpoints include the following: within-group changes in systolic AOBP from baseline to Week 12, changes in $\mathrm{K}^{+}$levels over time measured by a central laboratory and by local laboratories, proportion of patients with serum $\mathrm{K}^{+}$ $\geq 5.5 \mathrm{mEq} / \mathrm{L}$, average daily dose and cumulative dose of spironolactone, time to discontinuation of spironolactone, and changes in albuminuria (urine albumin to creatinine ratio) from baseline to Week 12. HBP data will be examined via exploratory analysis. In addition, the EuroQol Group 5-domain 5-level (EQ-5D-5L) questionnaire, a generic patient-reported instrument for measuring incremental changes in health, will be collected at baseline and Week 12 (or early termination) [24]. The questionnaire is composed of 5 questions representing 5 health domains: mobility, self-care, usual activities, pain/discomfort, and anxiety/depression.

\section{Sample Size Determination}

AMBER plans to enroll approximately 290 patients at 60 sites in the United States, South Africa, the United Kingdom, France, Germany, Croatia, Hungary, Georgia, and Ukraine. The planned sample size ensures that at least 280 patients will be available for the 


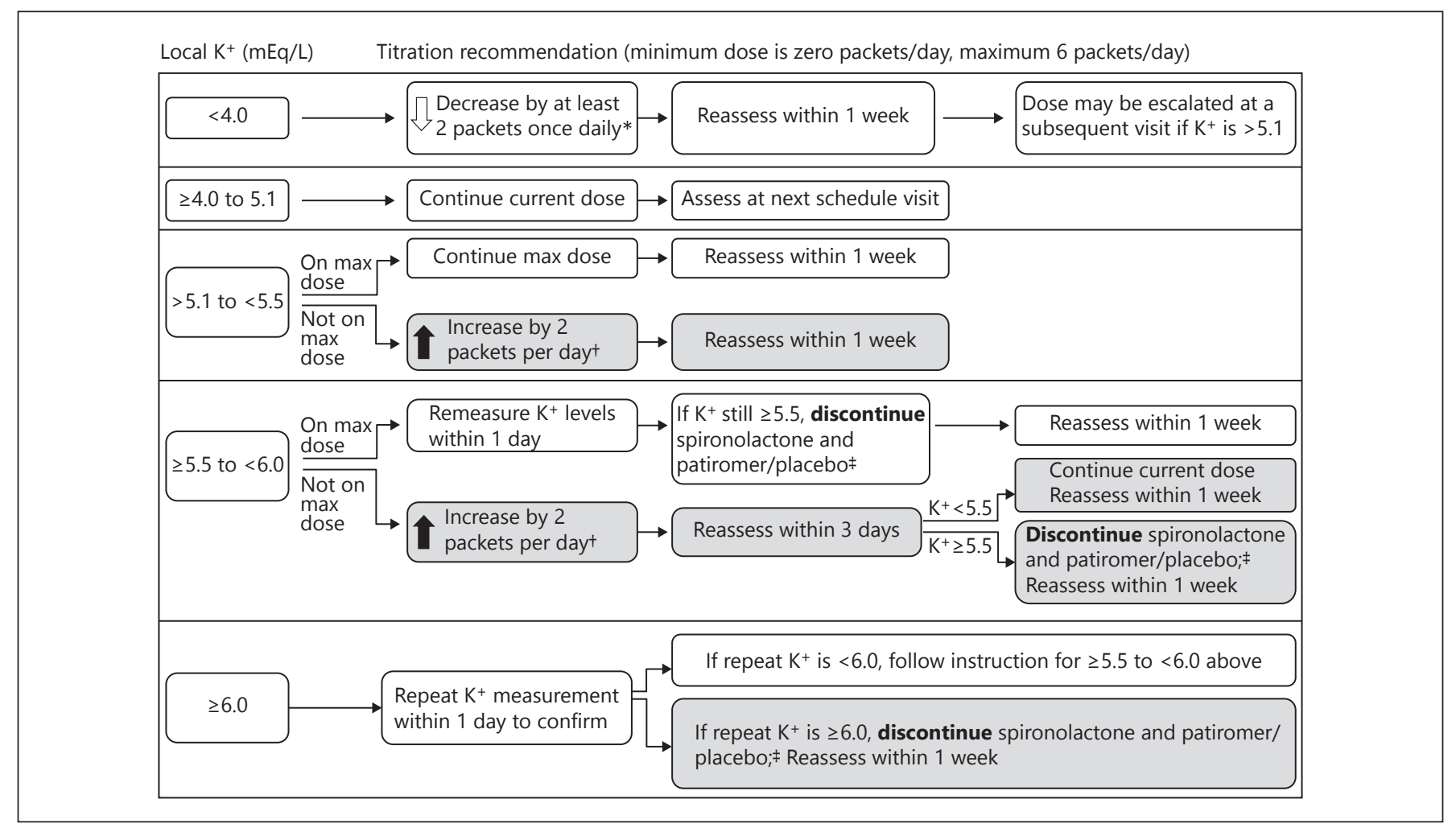

Fig. 3. Patiromer dosing algorithm. $\mathrm{K}^{+}$, potassium. ${ }^{*}$ Each packet contains patiromer $(4.2 \mathrm{~g})$ or microcrystalline cellulose placebo. ${ }^{\dagger}$ All dose increases should be made no less than 1 week apart. ${ }^{\ddagger}$ After discontinuation, hyperkalemia may be treated at any time using standard of care per Investigator judgment.

primary endpoint analysis, allowing for the possibility that up to 10 randomized patients will not take any study medication. A cohort of 280 patients provides $90 \%$ power to detect a difference between treatment groups of $\geq 20 \%$ in the proportion of patients remaining on spironolactone at Week 12 at an $\alpha=0.05$. Assuming a dropout rate of $15 \%$, the sample size also provides approximately $80 \%$ power to detect a $4 \mathrm{~mm} \mathrm{Hg}$ difference between treatment groups in change in systolic AOBP from Baseline to Week 12 (or to the last available AOBP before addition of any new antihypertensive medications or change in any of the baseline antihypertensive medications).

\section{Monitoring Changes in Renal Function}

Acute reductions in GFR have been reported with the initiation of spironolactone, similar to those observed when starting an ACEI or ARB, and have been attributed to transient changes in glomerular hemodynamics $[6,25]$. Similar to renin-angiotensin blocker agents, these changes typically do not impact long-term renal function [26-28]. Therefore, subjects will be monitored for changes in renal function, especially during periods of medication changes or adjustments. Kidney Disease Outcomes Quality Initiative (KDOQI) recommendations for the detection and management of early decreases in GFR when initiating ACEIs or ARBs will be considered in this study for spironolactone when reductions in renal function occur [29].

Extrapolating from the KDOQI guidelines for ACEI/ARBs, in this study, we define an early decline in eGFR as a $>15 \%$ reduction from baseline within 4 weeks of starting spironolactone; no change in spironolactone dose is needed for decreases in eGFR $\leq 30 \%$. However, for decreases in eGFR of $30-50 \%$, the spironolactone dose should be decreased and eGFR monitored weekly; spironolactone should be discontinued if eGFR does not return to within $30 \%$ of baseline within 4 weeks. For eGFR decreases $>50 \%$, spironolactone should be discontinued and eGFR monitored weekly until it returns to within $15 \%$ of baseline.

\section{Assessments}

AOBP will be measured at all visits. These measurements will be performed before other scheduled assessments except for the S4 and Week 12 visits, when EQ-5D-5L will be administered first. A 24-h urine collection will be performed prior to the baseline visit, and the first 3 morning urine samples will be collected at baseline and periodically throughout the study for central laboratory assessment of albuminuria (urine albumin-to-creatinine ratio). Serum $\mathrm{K}^{+}$will be assessed locally and by a central laboratory at all study visits. The central laboratory will analyze all other laboratory tests, including serum and urine chemistry, creatinine, and hematology. $\mathrm{N}$-terminal pro b-type natriuretic peptide levels will also be measured as a biomarker of cardiac stress. Spironolactone levels in blood will be measured by mass spectrometry. Adverse events will be monitored at all visits, and physical examinations and 12-lead electrocardiograms will be performed at the S1 and Week 12 visits. 
Statistical Plan

The primary endpoint will be compared between treatment groups using the Cochran-Mantel-Haenszel test, stratified by baseline $\mathrm{K}^{+}$category ( 4.3 to $<4.7$ vs. 4.7 to $5.1 \mathrm{mEq} / \mathrm{L}$ ) and presence/absence of diabetes mellitus. The secondary endpoint will be analyzed using an analysis of covariance (ANCOVA) model, with baseline systolic AOBP as a covariate and baseline serum $\mathrm{K}^{+}$and presence/absence of diabetes mellitus as categorical factors. The primary and secondary endpoints will also be evaluated in several pre-specified subgroups of interest, including gender, age group ( $<65$ vs. $\geq 65$ years), and diabetes (yes vs. no). Change in systolic AOBP at Week 12 will be analyzed with an ANCOVA model for patients with non-missing systolic AOBP at both baseline and Week 12, and additionally using a repeated measures mixed model that includes all patients with at least one post-baseline measurement of systolic AOBP. These models will also include baseline systolic AOBP as a covariate and presence/absence of diabetes mellitus and baseline serum $\mathrm{K}^{+}$as categorical factors. Time to discontinuation of spironolactone will be analyzed using KaplanMeier methods, and average daily and cumulative dose of spironolactone will be analyzed using ANCOVA methods. Change in albuminuria, serum $\mathrm{K}^{+}$levels, EQ-5D-5L questionnaire results, and safety parameters will be summarized descriptively.

\section{Characteristics of Randomized Patients}

Baseline characteristics, analyzed as of March 2018 for 146 randomized patients (of a targeted 290 patients) who had completed through Week 12, are shown in Table 1. Overall, the mean (SD) baseline age is 69.3 (10.9) years, with $52.1 \%$ male, and $99.3 \%$ of White race. Roughly half of the patient population (47.3\%) has diabetes mellitus, with a mean time since the diagnosis of 13.4 years; $50.7 \%$ have a history of heart failure. The mean (SD) baseline values are as follows: for eGFR, 35.7 (7.7) $\mathrm{mL} / \mathrm{min} / 1.73 \mathrm{~m}^{2}$, for serum $\mathrm{K}^{+}, 4.68(0.25) \mathrm{mEq} / \mathrm{L}$, for systolic AOBP, $144.3(6.8) \mathrm{mm} \mathrm{Hg}$, and for diastolic AOBP, 79.7 (12.1) $\mathrm{mm} \mathrm{Hg}$.

\section{Discussion}

Spironolactone has been shown to reduce blood pressure in the general RHTN population $[16,17]$, and in RHTN patients with heart failure with preserved ejection fraction [30]. It has been found to be a more effective BPlowering agent compared with other medication classes, as demonstrated in PATHWAY-2 [18]. Despite having a high prevalence of RHTN, patients with clinically significant CKD are typically excluded from treatment trials, as these patients have higher risk and often develop clinically significant hyperkalemia when exposed to renin-an-
Table 1. Baseline characteristics of randomized patients*

\begin{tabular}{|c|c|}
\hline Characteristic & $\begin{array}{l}\text { Randomized } \\
(n=146)\end{array}$ \\
\hline Age, years, mean (SD) & $69.3(10.9)$ \\
\hline$\geq 65$ at informed consent, $n(\%)$ & $104(71.2)$ \\
\hline Male, $n(\%)$ & $76(52.1)$ \\
\hline White race, $n(\%)$ & $145(99.3)$ \\
\hline \multicolumn{2}{|l|}{ Ethnicity, $n(\%)$} \\
\hline Hispanic or Latino & $12(8.2)$ \\
\hline Non-Hispanic and non-Latino & $133(91.1)$ \\
\hline Not reported & $1(0.7)$ \\
\hline Diabetes mellitus, $n$ (\%) & $69(47.3)$ \\
\hline Time since diagnosis, years, mean (SD) & $13.4(8.3)$ \\
\hline Serum potassium (local), mEq/L, mean (SD) & $4.68(0.25)$ \\
\hline eGFR, $\mathrm{mL} / \mathrm{min} / 1.73 \mathrm{~m}^{2}$, mean $(\mathrm{SD})$ & $35.7(7.7)$ \\
\hline \multicolumn{2}{|l|}{ Automated office blood pressure, $\mathrm{mm} \mathrm{Hg}$, mean (SD) } \\
\hline Systolic & $144.3(6.8)$ \\
\hline Diastolic & $79.7(12.1)$ \\
\hline \multicolumn{2}{|l|}{ Antihypertensive medications, $n(\%)$} \\
\hline Beta blockers & $89(61.0)$ \\
\hline Calcium channel blockers & $105(71.9)$ \\
\hline Non-RAASi diuretics & $132(90.4)$ \\
\hline RAASi & $145(99.3)$ \\
\hline Other & $34(23.3)$ \\
\hline \multicolumn{2}{|l|}{ History of hyperkalemia associated with the } \\
\hline use of ACEi, ARB, or MRA, $n(\%)$ & $2(1.4)$ \\
\hline Cardiac disorders, $n(\%)$ & $88(60.3)$ \\
\hline Atrial fibrillation & $14(9.6)$ \\
\hline Atrial flutter & $1(0.7)$ \\
\hline History of stroke or cerebrovascular accident, $n(\%)$ & $18(12.3)$ \\
\hline History of myocardial infarction, $n(\%)$ & $31(21.2)$ \\
\hline History of heart failure, $n(\%)$ & $74(50.7)$ \\
\hline Ejection fraction, mean (SD) & $47.5(9.6)$ \\
\hline Preserved ejection fraction, $n(\%)$ & $24(16.4)$ \\
\hline Reduced ejection fraction, $n(\%)$ & $36(24.7)$ \\
\hline Unknown & $14(9.6)$ \\
\hline \multicolumn{2}{|l|}{ NYHA class, $n(\%)$} \\
\hline I & $11(7.5)$ \\
\hline II & $55(37.7)$ \\
\hline III & $8(5.5)$ \\
\hline
\end{tabular}

* Analyzed as of March 2018 for 146 randomized patients (of a targeted 290 patients) who had completed through Week 12.

$\mathrm{ACEi}$, angiotensin-converting enzyme inhibitor; $\mathrm{ARB}$, angiotensin receptor blocker; eGFR, estimated glomerular filtration rate; MRA, mineralocorticoid receptor antagonist; NYHA, New York Heart Association; RAASi, renin-angiotensin-aldosterone system inhibitor; SD, standard deviation.

giotensin blocking agents and MRAs. Hence, the CKD population with RHTN remains understudied and underserved.

The AMBER study design was based on the hypothesis that concomitant use of spironolactone and patiromer in CKD patients with RHTN will better manage the risk of hyperkalemia, and thereby allow more persistent use of spironolactone - which ultimately would lead to improved blood pressure control. A unique aspect of the AMBER trial is that it will measure AOBP while the patient is unat- 
tended in the clinical setting, thereby minimizing potential "white coat hypertension". This methodology was used in most patients in the SPRINT trial and the values were correlated with ambulatory blood pressure during that study [31]. The values from this methodology will lead to a more precise diagnosis of RHTN. At the time the study was begun, the gold standard for defining hypertension was the awake ambulatory blood pressure. AOBP readings have been shown to be equivalent, and so a cut point of $135 \mathrm{~mm}$ $\mathrm{Hg}$ was used as had been used for ambulatory BP [4, 32, 33]. Although the upper limit of automated office systolic blood pressure of $160 \mathrm{~mm} \mathrm{Hg}$ excludes patients with more severe RHTN, it was selected because higher systolic AOBP would likely compel investigators to add additional antihypertensive medications during the treatment period if blood pressure remained uncontrolled, which could confound interpretation of study results.

Eligibility also requires an eGFR of $25-45 \mathrm{~mL} /$ $\mathrm{min} / 1.73 \mathrm{~m}^{2}$ (mean of 2 screening values). Risk of hyperkalemia during spironolactone therapy is substantially increased with eGFR $<45 \mathrm{~mL} / \mathrm{min} / 1.73 \mathrm{~m}^{2}$ [20]. Furthermore, spironolactone is contraindicated for patients with acute renal insufficiency or significant impairment of renal excretory function [34]. To minimize patient risk, laboratory assessment will be performed regularly through the trial, including serum creatinine, eGFR, and potassium measurements. An initial decrease in renal function is expected following the addition of spironolactone to a background regimen of 3 antihypertensive agents that include a diuretic and renin-angiotensin blocking agent. Investigators are recommended to follow KDOQI guidelines for the detection and management of early decreases in eGFR. According to KDOQI recommendations, significant declines from baseline in eGFR $>30 \%$ may require dose adjustment or discontinuation of spironolactone [29].

An important consideration for the trial design was the use of 24-h ambulatory blood pressure monitoring. While we recognize the value of this technique, we reasoned that given frequent titrations of the drug and downstream blood pressure measurements, we may have missing data if we required frequent 24-h ambulatory blood pressure monitoring. Given that the pattern of missing data may not be random, it may introduce bias in the study design. In view of the important relationships observed between AOBP and CV outcomes, we chose this as the primary endpoint in this trial.

If the primary endpoint is positive in the AMBER study, it would indicate that patiromer effectively enabled persistent spironolactone use in CKD patients by maintaining serum $\mathrm{K}^{+}$in a normal range and mini- mizing the risk of hyperkalemia. If the secondary endpoint assessing reductions in blood pressure is also positive, it would indicate that the ability of patiromer to permit chronic spironolactone use translates into better blood pressure control, extending previous findings from PATHWAY-2 and other studies to the CKD population with RHTN [18, 30, 35-37]. Finally, because albuminuria is a marker of cardiovascular and renal outcomes [38-40], positive reductions in albuminuria favoring the spironolactone and patiromer arm may set the stage for a renal outcomes study with these agents.

\section{Acknowledgments}

Writing and editorial support services were provided by $\mathrm{Mi}$ chael P. Bennett of Impact Communication Partners, Inc., and funded by Relypsa, Inc., a Vifor Pharma Group Company. Relypsa Inc., a Vifor Pharma Group Company acknowledges the support of the National Institute for Health Research Clinical Research Network (NIHR CRN).

\section{Disclosure Statement}

R.A.: consulting for Abbvie, Amgen, AstraZeneca, Bayer, Boehringer Ingelheim, Ironwood, Celgene, Daiichi-Sankyo, Eli Lilly, Gilead, GlaxosSmithKline, Johnson \& Johnson, Merck, Novartis, Sandoz, Sanofi, Relypsa and ZS Pharma; P.R.: honoraria from AstraZeneca, Bayer, CVRx, Daichii-Sankyo, Fresenius, Gambro, G3P, HAC, Novartis, Relypsa, Sanofi, Sarfez, Servier, Stealth Peptides, and Vifor Fresenius Medical Care Renal Pharma; research grants from AstraZeneca, BG Medicine, BMS and Roche; and travel grants from AstraZeneca, Daichii-Sankyo, Gambro, Novartis, Servier, and Takeda; Cofounder: CardioRenal B.W.: consultant for clinical trials for Relypsa/Vifor Pharma, Novartis and Vascular Dynamics, honoraria for lectures from Novartis, Daiichi-Sankyo, Servier, and Boehringer Ingelheim; W.B.W.: Consultant to Relypsa (AMBER Steering Committee); D.G., M.R.M., S.W., S.A., and A.R.: employment by Relypsa, Inc., a Vifor Pharma Group Company.

\section{Funding Support}

This study was sponsored and funded by Relypsa, Inc., a Vifor Pharma Group Company.

\section{Author Contributions}

The authors made substantial contributions to the conception or design of the work (R.A., P.R., D.G., M.R.M., S.A., W.B.W., and B.W.), or to the acquisition, analysis, or interpretation of data for the work (all); participated in drafting and revising the manuscript (all); approved the final version to be published (all); and agreed to be accountable for all aspects of the work (all). 


\section{References}

1 Calhoun DA, Jones D, Textor S, Goff DC, Murphy TP, Toto RD, White A, Cushman WC, White W, Sica D, Ferdinand K, Giles TD, Falkner B, Carey RM; American Heart Association Professional Education Committee: Resistant hypertension: diagnosis, evaluation, and treatment: a scientific statement from the American Heart Association Professional Education Committee of the Council for High Blood Pressure Research. Circulation 2008; 117:e510-e526.

2 Weber MA, Schiffrin EL, White WB, Mann S, Lindholm LH, Kenerson JG, Flack JM, Carter BL, Materson BJ, Ram CV, Cohen DL, Cadet JC, Jean-Charles RR, Taler S, Kountz D, Townsend RR, Chalmers J, Ramirez AJ, Bakris GL, Wang J, Schutte AE, Bisognano JD, Touyz RM, Sica D, Harrap SB: Clinical practice guidelines for the management of hypertension in the community: a statement by the American Society of Hypertension and the International Society of Hypertension. J Clin Hypertens (Greenwich) 2014;16: 14-26.

3 James PA, Oparil S, Carter BL, Cushman WC, Dennison-Himmelfarb C, Handler J, Lackland DT, LeFevre ML, MacKenzie TD, Ogedegbe O, Smith SC Jr, Svetkey LP, Taler SJ, Townsend RR, Wright JT Jr, Narva AS, Ortiz E: 2014 evidence-based guideline for the management of high blood pressure in adults: report from the panel members appointed to the Eighth Joint National Committee (JNC 8). JAMA 2014;311:507-520.

4 ESH/ESC Task Force for the Management of Arterial Hypertension. 2013 Practice guidelines for the management of arterial hypertension of the European Society of Hypertension (ESH) and the European Society of Cardiology (ESC). J Hypertens 2013;31:19251938.

5 Mancia G, Fagard R, Narkiewicz K, Redón J, Zanchetti A, Böhm M, Christiaens T, Cifkova R, De Backer G, Dominiczak A, Galderisi M, Grobbee DE, Jaarsma T, Kirchhof P, Kjeldsen SE, Laurent S, Manolis AJ, Nilsson PM, Ruilope LM, Schmieder RE, Sirnes PA, Sleight P, Viigimaa M, Waeber B, Zannad F; Task Force Members: 2013 ESH/ESC Guidelines for the management of arterial hypertension: the Task Force for the management of arterial hypertension of the European Society of Hypertension (ESH) and of the European Society of Cardiology (ESC). J Hypertens 2013; 31:1281-1357.

6 Kidney Disease Improving Global Outcomes. KDIGO clinical practice guideline for the management of blood pressure in chronic kidney disease. Kidney Int Suppl 2012;2: 337-414.

7 American Diabetes Association. Standards of Medical Care in Diabetes-2017. Diabetes Care 2017;40:S1-S134.

8 de la Sierra A, Segura J, Banegas JR, Gorostidi M, de la Cruz JJ, Armario P, Oliveras A,
Ruilope LM: Clinical features of 8295 patients with resistant hypertension classified on the basis of ambulatory blood pressure monitoring. Hypertension 2011;57:898-902.

9 Wolley MJ, Stowasser M: Resistant hypertension and chronic kidney disease: a dangerous liaison. Curr Hypertens Rep 2016;18: 36-36.

10 Tanner RM, Calhoun DA, Bell EK, Bowling $\mathrm{CB}$, Gutiérrez OM, Irvin MR, Lackland DT, Oparil S, Warnock D, Muntner P: Prevalence of apparent treatment-resistant hypertension among individuals with CKD. Clin J Am Soc Nephrol 2013;8:1583-1590.

11 Bomback AS, Klemmer PJ: The incidence and implications of aldosterone breakthrough. Nat Clin Pract Nephrol 2007;3:486-492.

12 Blasi ER, Rocha R, Rudolph AE, Blomme EA, Polly ML, McMahon EG: Aldosterone/salt induces renal inflammation and fibrosis in hypertensive rats. Kidney Int 2003;63:1791-1800.

13 Hollenberg NK: Aldosterone in the development and progression of renal injury. Kidney Int 2004;66:1-9.

14 Lastra G, Dhuper S, Johnson MS, Sowers JR: Salt, aldosterone, and insulin resistance: impact on the cardiovascular system. Nat Rev Cardiol 2010;7:577-584.

15 Narayan H, Webb DJ: New evidence supporting the use of mineralocorticoid receptor blockers in drug-resistant hypertension. Curr Hypertens Rep 2016;18:34-34.

16 Dahal K, Kunwar S, Rijal J, Alqatahni F, Panta R, Ishak N, Russell RP: The effects of aldosterone antagonists in patients with resistant hypertension: a meta-analysis of randomized and nonrandomized studies. Am J Hypertens 2015;28:1376-1385.

17 Guo H, Xiao Q: Clinical efficacy of spironolactone for resistant hypertension: a meta analysis from randomized controlled clinical trials. Int J Clin Exp Med 2015;8:72707278.

18 Williams B, MacDonald TM, Morant S, Webb DJ, Sever P, McInnes G, Ford I, Cruickshank JK, Caulfield MJ, Salsbury J, Mackenzie I, Padmanabhan S, Brown MJ; British Hypertension Society's PATHWAY Studies Group: Spironolactone versus placebo, bisoprolol, and doxazosin to determine the optimal treatment for drug-resistant hypertension (PATHWAY-2): a randomised, double-blind, crossover trial. Lancet 2015;386:2059-2068.

19 Bolignano D, Palmer SC, Navaneethan SD, Strippoli GF: Aldosterone antagonists for preventing the progression of chronic kidney disease. Cochrane Database Syst Rev 2014; 4:CD007004.

20 Khosla N, Kalaitzidis R, Bakris GL: Predictors of hyperkalemia risk following hypertension control with aldosterone blockade. Am J Nephrol 2009;30:418-424.

21 Veltassa $^{\circledR}$ (patiromer): SmPC. European Medicines Agency. Available at: http://www. ema.europa.eu/ema/index.jsp?curl=pages/ medicines/human/medicines/004180/human_med_002141.jsp\&mid=WC0b0 (Last accessed: May 2018).

22 Veltassa $^{\circledR}$ (patiromer): Prescribing Information. Redwood City, Relypsa, Inc., 2018. https://www.accessdata.fda.gov/scripts/cder/ daf/ (last accessed May 2018).

23 Pitt B, Anker SD, Bushinsky DA, Kitzman DW, Zannad F, Huang IZ; PEARL-HF Investigators: Evaluation of the efficacy and safety of RLY5016, a polymeric potassium binder, in a double-blind, placebo-controlled study in patients with chronic heart failure (the PEARL-HF) trial. Eur Heart J 2011;32:820828 .

24 Herdman M, Gudex C, Lloyd A, Janssen M, Kind P, Parkin D, Bonsel G, Badia X: Development and preliminary testing of the new five-level version of EQ-5D (EQ-5D-5L). Qual Life Res 2011;20:1727-1736.

25 Bianchi S, Batini V, Bigazzi R: The renal effects of mineralocorticoid receptor antagonists. International J Cardiol 2015;200:20-24.

26 Bianchi S, Bigazzi R, Campese VM: Longterm effects of spironolactone on proteinuria and kidney function in patients with chronic kidney disease. Kidney Int 2006;70:21162123.

27 van den Meiracker AH, Baggen RGA, Pauli S, Lindemans A, Vulto AG, Poldermans D, Boomsma F: Spironolactone in type 2 diabetic nephropathy: effects on proteinuria, blood pressure and renal function. J Hypertens 2006;24:2285-2292.

28 Fourkiotis V, Vonend O, Diederich S, Fischer E, Lang K, Endres S, Beuschlein F, Willenberg HS, Rump LC, Allolio B, Reincke M, Quinkler M: Effectiveness of eplerenone or spironolactone treatment in preserving renal function in primary aldosteronism. Eur J Endocrinol 2012;168:75-81.

29 Kidney Disease Outcomes Quality Initiative (K/DOQI). K/DOQI clinical practice guidelines on hypertension and antihypertensive agents in chronic kidney disease. Am J Kidney Dis 2004;43:S1-S290.

30 Rossignol P, Claggett BL, Liu J, Vardeny O, Pitt B, Zannad F, Solomon S: Spironolactone and resistant hypertension in heart failure with preserved ejection fraction. Am J Hypertens 2018;31:407-414.

31 Wright JT, Williamson JD, Whelton PK, Snyder JK, Sink KM, Rocco MV, Reboussin DM, Rahman M, Oparil S, Lewis CE, Kimmel PL, Johnson KC, Goff DC Jr, Fine LJ Cutler JA, Cushman WC, Cheung AK, Ambrosius WT; SPRINT Research Group: A randomized trial of intensive versus standard blood-pressure control. N Engl J Med 2015;373:2103-2116.

32 Myers MG, Kaczorowski J, Paterson JM, Dolovich L, Tu K: Thresholds for diagnosing hypertension based on automated office blood pressure measurements and cardiovascular risk. Hypertension 2015;66:489-495. 
33 Chobanian AV, Bakris GL, Black HR, Cushman WC, Green LA, Izzo JL Jr, Jones DW, Materson BJ, Oparil S, Wright JT Jr, Roccella EJ; National Heart, Lung, and Blood Institute Joint National Committee on Prevention, Detection, Evaluation, and Treatment of High Blood Pressure; National High Blood Pressure Education Program Coordinating Committee: The seventh report of the Joint National Committee on prevention, detection, evaluation, and treatment of high blood pressure: the JNC 7 report. JAMA 2003;289:2560-2572.

34 Aldactone $^{\circledR}$ (spironolactone): Prescribing Information. New York, Pfizer, Inc., 2014.

35 Nishizaka MK, Zaman MA, Calhoun DA: Efficacy of low-dose spironolactone in subjects with resistant hypertension. Am J Hypertens 2003; 16:925-930.
36 Chapman N, Dobson J, Wilson S, Dahlof B, Sever PS, Wedel H, Poulter NR; Anglo-Scandinavian Cardiac Outcomes Trial Investigators: Effect of spironolactone on blood pressure in subjects with resistant hypertension. Hypertension 2007;49:839-845.

37 Goodman WG, Goldin J, Kuizon BD, Yoon C, Gales B, Sider D, Wang Y, Chung J, Emerick A, Greaser L, Elashoff RM, Salusky IB: Coronary-artery calcification in young adults with end-stage renal disease who are undergoing dialysis. N Engl J Med 2000;342:14781483.

38 Carrero JJ, Grams ME, Sang Y, Ärnlöv J, Gasparini A, Matsushita K, Qureshi AR, Evans $\mathrm{M}$, Barany $\mathrm{P}$, Lindholm B, Ballew SH, Levey AS, Gansevoort RT, Elinder CG, Coresh J: Albuminuria changes are associ- ated with subsequent risk of end-stage renal disease and mortality. Kidney Int 2017;91: 244-251.

39 Savarese G, Dei Cas A, Rosano G, D'Amore C, Musella F, Mosca S, Reiner MF, Marchioli R, Trimarco B, Perrone-Filardi P: Reduction of albumin urinary excretion is associated with reduced cardiovascular events in hypertensive and/or diabetic patients. A meta-regression analysis of 32 randomized trials. Int J Cardiol 2014;172:403-410.

40 Schmieder RE, Mann JF, Schumacher H, Gao P, Mancia G, Weber MA, McQueen M, Koon T, Yusuf S; ONTARGET Investigators: Changes in albuminuria predict mortality and morbidity in patients with vascular disease. J Am Soc Nephrol 2011;22:13531364. 